\title{
Anterior capsulotomy for obsessive-compulsive disorder: a review of old and new literature
}

\author{
Joshua Pepper, BSc, MBBS, ${ }^{1}$ Ludvic Zrinzo, MD, PhD, FRCS, ${ }^{2}$ and Marwan Hariz, MD, PhD ${ }^{3}$ \\ 1'Department of Neurosurgery, Queen Elizabeth Hospital, Birmingham, United Kingdom; '2Unit of Functional Neurosurgery, Queen \\ Square, London, United Kingdom; and 'Department of Clinical Neuroscience, Umeå University, Umeå, Sweden
}

\begin{abstract}
Over the last two decades, deep brain stimulation (DBS) has gained popularity as a treatment of severe and medically refractory obsessive-compulsive disorder (OCD), often using brain targets informed by historical lesional neurosurgical procedures. Paradoxically, the use of DBS in OCD has led some multidisciplinary teams to revisit the use of lesional procedures, especially anterior capsulotomy $(A C)$, although significant aversion still exists toward the use of lesional neurosurgery for psychiatric disorders. This paper aims to review all literature on the use of AC for OCD to examine its effectiveness and safety profile.
\end{abstract}

All publications on AC for OCD were searched. In total 512 patients were identified in 25 publications spanning 19612018. In papers where a Yale-Brown Obsessive Compulsive Scale (Y-BOCS) score was available, $73 \%$ of patients had a clinical response (i.e., > 35\% improvement in Y-BOCS score) and $24 \%$ patients went into remission (Y-BOCS score < 8). In the older publications, published when the Y-BOCS was not yet available, $90 \%$ of patients were deemed to have had a significant clinical response and $39 \%$ of patients were considered symptom free. The rate of serious complications was low.

In summary, AC is a safe, well-tolerated, and efficacious therapy. Its underuse is likely a result of historical prejudice rather than lack of clinical effectiveness.

https://thejns.org/doi/abs/10.3171/2019.4.JNS19275

KEYWORDS obsessive-compulsive disorder; psychosurgery; anterior capsulotomy; Gamma Knife; focused ultrasound; radiofrequency ablation; functional neurosurgery

$\mathrm{P}$ SYCHOSURGERY in all its guises often provokes a mélange of reactions. Recalling the era of unselective lobotomy from over half a century ago rouses fear and revulsion. ${ }^{19}$ However, currently there is cautious optimism that psychosurgery or neurosurgery for mental disorders (NMD) has learned from its past. The field of NMD is undergoing a renaissance, buoyed by the popularity of deep brain stimulation (DBS) for movement disorders. Paradoxically, this surge in interest in DBS in psychiatry has reinvigorated the field of stereotactic lesional neurosurgery for mental illness.

Current stereotactic lesional procedures are vastly different from those of the 1950s through 1970s, having benefited immensely from new imaging, new technology, closer multidisciplinary work, and more robust follow-up. ${ }^{14}$ However, there is consternation that their use represents a backward step in the evolution of functional neurosurgery. Nevertheless, many stereotactic lesional procedures of the past showed promising and successful results. ${ }^{2,18}$ Indeed, a small double-blind randomized controlled trial of capsulotomy for OCD has recently demonstrated significantly greater improvement in patients undergoing capsulotomy versus controls. ${ }^{22}$ "Lesional surgery" is widely accepted in the field of epilepsy, and neurologists routinely refer patients for resection or ablation of significant volumes of brain tissue (for example, in temporal lobe epilepsy). However, psychiatrists are generally much more reticent to consider referral of patients for stereotactic ablation. History informs the selection of new DBS targets ${ }^{29}$ and also helps develop and modernize the "old" lesional procedures that have been underused for a vast pool of severe, chronic, and refractory psychiatric diseases.

Obsessive-compulsive disorder (OCD) is a psychiatric condition that often runs a chronic and debilitating course. It affects $2 \%$ of the global population and in many patients continues to worsen or becomes refractory to medical and

ABBREVIATIONS AC = anterior capsulotomy; DBS = deep brain stimulation; $\mathrm{GK}=$ Gamma Knife; ICH = intracerebral hemorrhage; NMD = neurosurgery for mental disorders; OCD = obsessive-compulsive disorder; SSRI = selective serotonin reuptake inhibitor; Y-BOCS = Yale-Brown Obsessive Compulsive Scale.

SUBMITTED January 30, 2019. ACCEPTED April 29, 2019.

INCLUDE WHEN CITING Published online October 11, 2019; DOI: 10.3171/2019.4.JNS19275. 
psychiatric management. ${ }^{9,40}$ It is in these patients and within the context of a multidisciplinary team that neurosurgery should be considered. A number of brain targets have historically been selected in the treatment of severe OCD; procedures currently performed include anterior capsulotomy (AC), ${ }^{22}$ cingulotomy, ${ }^{4}$ and subcaudate tractotomy. ${ }^{42}$ The anterior capsule has been one of the most widely used targets, with reported remission rates of $30 \%$ and clinical response rates of $75 \%$ in some publications. . $^{2,5,18,30}$ Therefore, this data, no matter how historical, deserves analysis and evaluation. The accepted primary outcome measure in modern medical literature is the Yale-Brown Obsessive Compulsive Scale (Y-BOCS), published in $1989 .^{12}$

The aim of this paper is to assess both historical and modern outcomes of AC performed by any method (radiofrequency ablation, Gamma Knife [GK] radiosurgery, mechanical leukotomy, or MR-guided focused ultrasound) in the treatment of OCD in order to inform further treatment for patients with this highly refractory and difficultto-treat condition.

\section{Methods}

Publications on AC for OCD were obtained from the PubMed database, from proceedings of neurosurgical meetings, and from references from relevant papers published before September 2018. The search criteria used are in accordance with guidelines published in the Cochrane Library. PubMed was searched using a combination of optimal search strategies and the phrase(s): surg* OR neurosurg* OR psychosurg* OR radiosurg* OR capsuloto* OR tractoto* OR leucoto* OR leukoto* OR loboto* OR radio-surg* OR radiosurg* OR stereota* OR stereo-ta* OR gamma kni* OR gamma-ra* OR deep brain stimulation OR DBS OR neurosurgical procedures/ AND obsessive compuls* OR obsessive-compuls* OR mood disorders OR anxiety disorders.

The included publications were all studies in which patients with obsessive-compulsive disorder/neurosis underwent AC by any surgical method. Where possible, details of baseline characteristics (diagnosis of OCD, neurosurgical procedure conducted, duration of OCD, age at surgery, Y-BOCS score, social functioning) and outcome (followup time, Y-BOCS or scoring system used at last follow-up, comment on social functioning) were collected. Whenever possible, duplicate cases were identified and removed.

Papers were also screened with respect to reported adverse events. Serious adverse events were defined as those that would contribute significantly to morbidity (infection, epilepsy, intracranial hemorrhage) or mortality, including suicide within the first 12 months after surgery. Persisting adverse events were defined as new-onset symptoms that persisted for more than 8 weeks after surgery. These could include headache, dizziness, nausea, sleep disturbance, apathy, disinhibition, other personality changes, and other symptoms. Whenever there was uncertainty about an adverse event (e.g., the length of time it lasted) it was still included in the results.

For papers reporting on patients without Y-BOCS scores, considered "old" publications, patients were grouped by outcome according to a combination of analy- sis of social comments made about patients, the authors' impression, and any scoring system described in the publication.

The outcome group criteria used for "old" publications were as follows: Group A-symptom free/return to normal life activities; Group B-symptoms much improved, independent, back to work with some help; Group Csymptoms and level of social functioning improved, back to work or conducting some normal activities with support; Group D-no or minimal improvement of symptoms that has no useful impact on social/work functioning; Group E-worse.

For papers reporting on patients with a Y-BOCS score, outcome was determined as follows. Remission requires that Y-BOCS scores drop below 8, considered equivalent to Group A above. Response is defined as 35\% improvement or more in Y-BOCS, considered equivalent to Group $\mathrm{C}$ above. Nonresponder is when remission or response criteria are not met, considered equivalent to Group D above. Worse indicates a worsening of the Y-BOCS score from baseline, considered equivalent to Group $\mathrm{E}$ above.

When individual patient data was not available group averages were used.

\section{Statistical Analysis}

Mean values were calculated. The Student t-test was used to compare continuous data. Fisher's exact test, using a $2 \times 2$ contingency table, was used to compare the outcomes and complication rates in patients who had AC. A p value $<0.05$ was considered statistically significant.

\section{Results}

In total, 25 studies and 512 patients were identified in publications from 1961 through September 2018. In the "new" publication group, there were 16 studies $^{3,5,6,8,13,16,17}$, $20-23,30,34,37,38,43$ reporting outcome for 278 patients, and in

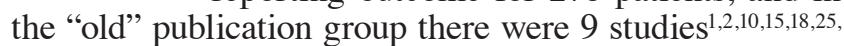
$27,28,36$ reporting outcome for 234 patients.

\section{Baseline Characteristics}

Table 1 ("new" publications) and Table 2 ("old" publications) present baseline details of the number of patients in each study, age at surgery, length of follow-up, duration of OCD, and details of the surgical procedure. Table 3 summarizes the baseline characteristics of the patients in the 2 publication groups.

\section{Year of Publication}

The number of published cases rapidly increased from the 1960s until the 1980 s. There was a paucity of new publications from the 1980s and a clear resurgence from 2000 until the present (Fig. 1).

\section{Outcome}

Over 7 in 10 (201 of 278) patients in the "new" group had a clinically significant response, with $24 \%$ (66 of 278) going into remission. In the "old" group, over $90 \%$ of patients (211 of 234) were considered to have a clinically significant response (outcome $\mathrm{A}, \mathrm{B}$, or $\mathrm{C}$ ), with almost 
TABLE 1. Summary of clinical and demographic characteristics of patients in "new" AC publications

\begin{tabular}{|c|c|c|c|c|c|c|c|}
\hline \multirow[b]{2}{*}{ Authors \& Year } & \multirow{2}{*}{$\begin{array}{l}\text { No. of } \\
\text { Pts }\end{array}$} & \multirow[b]{2}{*}{ Age in Yrs } & \multirow{2}{*}{$\begin{array}{l}\text { Sex } \\
(M: F)\end{array}$} & \multirow[b]{2}{*}{$\mathrm{FU}$ (mos) } & \multirow[b]{2}{*}{ Procedure } & \multicolumn{2}{|c|}{ Mean/(individual) YBOCS Scores } \\
\hline & & & & & & Preop & Postop \\
\hline Kim et al., 2018 & 11 & Mean: 33 & $5: 6$ & Mean: 24 & FUS, $51-56^{\circ} \mathrm{C}>3 \mathrm{sec}, 10-\mathrm{mm}$ ellipse & 34.4 & 21.3 \\
\hline Rasmussen et al., 2018 & 55 & Mean: 34 & $35: 20$ & Mean: 36 & GKS, bilat, max 180 Gy & 33.9 & 17.5 \\
\hline Liu et al., 2017 & 37 & NR & 26:11 & Mean: 60 & $\mathrm{RF} 70^{\circ} \mathrm{C} 60 \mathrm{sec} \& 80^{\circ} \mathrm{C} 70 \mathrm{sec}$ & 26.78 & 8.3 \\
\hline Lopes et al., 2014 & 12 & Mean: 34 & $7: 5$ & Mean: 55 & GKS, bilat, max 180 Gy & 33.1 & 17.3 \\
\hline Zhan et al., 2014 & 53 & Mean: 29 & $32: 21$ & Mean: 67.5 & $\mathrm{RF} 80^{\circ} \mathrm{C} 60 \mathrm{sec}$ & 24.7 & 6.5 \\
\hline Sheehan et al., 2013 & 5 & Mean: 37 & $3: 2$ & Mean: 22 & GKS, bilat, 140-160 Gy & 32 & 16 \\
\hline D'Astous et al., 2013 & 19 & Mean: 41 & $7: 12$ & Mean: 84 & BL, bilat, $20 \times 5-6 \mathrm{~mm}$ & 35 & 24 \\
\hline Kondziolka et al., 2011 & 3 & $37,40,55$ & $1: 2$ & Mean: 42 & GKS, bilat, $140-150 \mathrm{~Gy}$ & $(34,39,39)$ & $(24,7,18)$ \\
\hline Doshi, 2011 & 1 & 62 & 1:0 & 0.3 & RF, bilat, $75^{\circ} \mathrm{C}$ & (38) & (9) \\
\hline Gouvea et al., 2010 & 1 & 34 & $0: 1$ & 12 & GKS, bilat, 180 Gy & (37) & (0) \\
\hline Csigó et al., 2010 & 5 & Mean: 32 & $3: 2$ & Mean: 24 & RF: bilat & 38 & 18 \\
\hline Lopes et al., 2009 & 5 & Mean: 35 & $2: 3$ & Mean: 48 & GKS, bilat, 180 Gy & 32 & 21 \\
\hline Rück et al., 2008 & 24 & Mean: 41 & $10: 14$ & Mean: 124 & $\begin{array}{l}\text { GKS, bilat, } 160-200 \text { Gy \& RF, unilat or bilat, } \\
12-20 \mathrm{~mm}, 60^{\circ} \mathrm{C}\end{array}$ & 34 & 19 \\
\hline Liu et al., 2008 & 35 & Mean: 30 & $22: 13$ & Mean: 36 & RF, bilat $70-80^{\circ} \mathrm{C}$ & 21 & 4 \\
\hline Oliver et al., 2003 & 10 & Mean: 34 & $9: 6$ & Mean: 12 & RF, bilat, $18 \mathrm{~mm} 75^{\circ} \mathrm{C}$ & 30 & 17 \\
\hline Christensen et al., 2002 & 2 & 18,64 & $2: 0$ & Mean: 40 & RF, bilat, $65-70^{\circ} \mathrm{C}$ & $(30,31)$ & $(0,8)$ \\
\hline
\end{tabular}

$\mathrm{BL}$ = Bertrand leucotomy; FU = follow-up; FUS = focused ultrasound; GKS = Gamma Knife surgery; $\mathrm{NR}$ = not reported; pts = patients; $\mathrm{RF}=$ radiofrequency ablation.

The "new" publication group was defined as studies that included Y-BOCS scores.

$40 \%$ considered symptom free (outcome A) at long-term follow-up. See Fig. 2 for more details. Supplemental Tables 1-7 summarize outcome and adverse events in each included publication.

\section{Outcome by Procedure}

In total 90 patients described in the "new" publications underwent GK capsulotomy, and two-thirds of these patients (60 of 90) had a clinically significant response; 158 patients in the "new" publication group underwent radiofrequency ablation, and 79\% (125 of 158) had a clinically significant response; 19 patients in the "new" publication group underwent mechanical leukotome capsulotomy, with 7 being considered responders; and 11 patients in the "new" group underwent MR-guided focused ultrasound, with 6 being considered responders. Of the patients in the "old" publication group-that is, patients without a Y-BOCS score-93\% (13 of 14) of those who underwent GK capsulotomy were considered responders; of the 208 patients who underwent radiofrequency ablation, 189 had a clinically significant response; and of the 12 patients who underwent mechanical leukotomy, 9 responded (see Tables 1 and 2 and Supplemental Tables 1-7 for more detailed information).

\section{Adverse Events}

Figure 3 and Supplemental Tables 1-7 highlight reported adverse events in more detail. No surgical deaths were identified.

The rate of stroke was $2 \%$, although the majority of

TABLE 2. Summary of clinical and demographic characteristics of patients in "old" AC publications

\begin{tabular}{|c|c|c|c|c|c|c|}
\hline Authors \& Year & $\begin{array}{c}\text { No. of Pts } \\
\text { (no. evaluated) }\end{array}$ & $\begin{array}{l}\text { Age in Yrs } \\
\text { (range) }\end{array}$ & $\operatorname{Sex}(M: F)$ & $\begin{array}{c}\text { Duration of OCD, } \\
\text { Yrs (range) }\end{array}$ & $\begin{array}{l}\text { FU, Mos } \\
\text { (range) }\end{array}$ & Procedure \\
\hline Burzaco, 1981 & $85(85)$ & Mean: 36.4 & $39: 45$ & NR & $(8-180)$ & RF, bilat, $65^{\circ} \mathrm{C}, 40-50 \mathrm{sec}, 12-20 \times 8 \mathrm{~mm}$ \\
\hline Bingley et al., 1977 & $35(35)$ & Mean: 40 & $14: 21$ & Mean: 17 & Mean: 35 & RF, bilat $12-20 \times 8 \mathrm{~mm}$ \\
\hline Kullberg, 1977 & $8(8)$ & NR & NR & NR & NR & RF, bilat, $25 \times 10 \times 6 \mathrm{~mm}$ \\
\hline Mindus et al., 1995 & $24(22)$ & NR & NR & NR & NR & RF, bilat \\
\hline Rylander, 1979 & $45(45)$ & Mean: 40 & 18:27 & Mean: 17 & Mean: 39 & RF, bilat (38 pts); GKS, bilat (7 pts) \\
\hline Herner, 1961 & $18(18)$ & Mean: 37 & $3: 15$ & Mean: 13 & $(24-84)$ & RF, bilat \\
\hline Fodstad et al., 1982 & $2(2)$ & 42,50 & $0: 2$ & Mean: 25 & Mean: 24 & RF, bilat, height $8 \mathrm{~mm}$ \\
\hline Mindus et al., 1987 & $8(7)$ & Mean: 40 & $2: 5$ & Mean: 16 & Mean: 84 & GKS, bilat, 100-60 Gy \\
\hline Martinez et al., 1975 & $12(12)$ & NR & NR & NR & NR & BL, bilat \\
\hline
\end{tabular}

The "old" publication group was defined as studies that did not include Y-BOCS scores. 
TABLE 3. Baseline characteristics of patients in "new" and "old" publication groups

\begin{tabular}{lcc}
\hline \multicolumn{1}{c}{ Characteristic } & "New" Group & "Old" Group \\
\hline No. of pts & 278 & 234 \\
\hline No. of publications & 16 & 9 \\
\hline Male (\%) & 58 & 40 \\
\hline Mean age at op (yrs) & $35 \pm 12$ & 38 \\
\hline Mean duration of OCD (yrs) & $17 \pm 9$ & 15 \\
\hline Mean duration of FU (mos) & $61 \pm 50$ & 64 \\
\hline Mean preop Y-BOCS score & $30 \pm 7$ & NA \\
\hline
\end{tabular}

$\mathrm{NA}=$ not applicable.

Mean values are presented with standard deviations.

these either were asymptomatic or resulted in transient symptoms.

Nine $(1.8 \%)$ of 512 patients had intracerebral hemorrhage (ICH); in most of these cases, the hemorrhages were asymptomatic, however, in 2 cases $(0.4 \%)$, the patients required external ventricular drainage, and in 1 case $(0.2 \%)$, $\mathrm{ICH}$ resulted in permanent hemiplegia. ICH was more common and severe when a leukotome was used and if patients treated with leukotome capsulotomy are excluded the ICH rate is $1 \%$ (5 of 493 patients), with no reported long-term sequelae.

In total, 4 of 512 patients showed focal neurological deficit postoperatively. Of the patients in the "new" publication group, one developed hemiplegia secondary to ICH (a leukotome was used) ${ }^{6}$ and the other developed radiation necrosis ${ }^{37}$ after GK capsulotomy with a dose of $200 \mathrm{~Gy}$. In the "old" publication group, Bingley et al. ${ }^{1}$ reported on 2 patients who suffered from transient hemiparesis after subcortical infarct postoperatively.

Seizures were noted in 2 of 512 patients. ${ }^{30,37}$ One of these patients was considered to have developed epilepsy ${ }^{37}$ after developing significant brain edema, again after GK capsulotomy with a dose of $200 \mathrm{~Gy}$.

The most common side effect was weight gain, reported in 13\% of all patients (69 of 512). Weight gain is a welldocumented side effect of AC for OCD in both older ${ }^{1,2,15}$ and newer publications. ${ }^{5,37}$ In 1961, Herner $^{15}$ noted that the average weight gain was $11.6 \%$ of body weight. Other publications were not quite so explicit and merely noted that patients gained weight postoperatively and in some cases they returned to their preoperative weight. ${ }^{1,2}$ Rück et al..$^{37}$ noted that the average weight gain was $11 \mathrm{~kg}$ regardless of whether OCD patients underwent thermo-capsulotomy or GK capsulotomy. In case series with a smaller number of patients 1 or 2 patients from each study were noted to have gained a significant amount of weight, although the actual values are often not reported. $.10,23$

Almost $9 \%$ of patients (44 of 512) required a repeat procedure, often for nonresponse in the context of small lesion size. Rasmussen et al. ${ }^{34}$ reported on 15 patients who underwent single-shot GK radiosurgery, which was repeated in 13 cases due to nonresponse. Of these the average Y-BOCS score reduction in this group (single shot repeated) was reported as $42 \%$, with 7 of the original 15 patients considered responders. Rück et al. ${ }^{37}$ reported 7 pa-

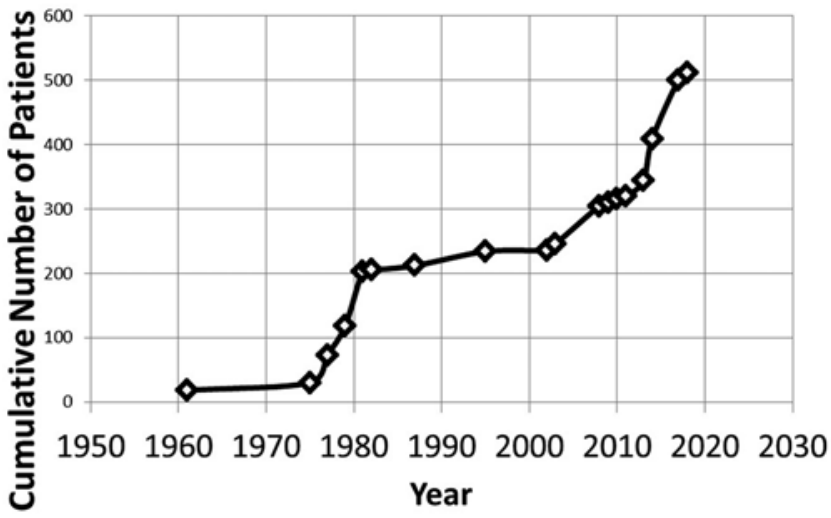

FIG. 1. Cumulative number of patients by publication year.

tients who required reoperation due to nonresponse with an average YBOCS reduction of $28 \%$ after reoperation, with 2 patients considered responders. Burzaco ${ }^{2}$ reoperated on 17 patients because of relapse. Information regarding the specific reason for and outcome after reoperation is often not reported.

\section{Discussion}

This paper summarizes the literature, both historical and contemporary, on the use of AC for OCD. Capsulotomy can be considered an effective and safe therapy for medically refractory OCD, with clinically meaningful results in over three-quarters of patients and remission in almost one-third of patients. Serious adverse events are rare and often associated with specific surgical techniques (use of a leukotome or excessively high radiation doses with GK capsulotomy).

Inconsistency in clinical outcome is likely a result of variability in the underlying pathology but may also be secondary to differences in lesion size and location. Unfortunately, many publications fail to include imaging or reports on exact lesion location and size. However, it has been suggested that smaller lesions placed in the most ventral aspect of the internal capsule are associated with better clinical outcomes. ${ }^{26}$

Anterior capsulotomy is by no means the first line or indeed the main treatment for OCD but should form a key component in selected patients who have not achieved sufficient symptom control after trying all other treatment options. Given its effectiveness and favorable side effect profile, $\mathrm{AC}$ is a viable tool in the surgical treatment of OCD and has almost certainly been underused since its inception seven decades ago.

\section{Old Literature}

In this literature review, "old" publications had a propensity for more positive results. It seems anomalous that patients operated on in the earlier era had better outcomes than those operated on in modern times. Indeed, it is likely that these results are in large part due to bias at all levels. Part of this problem was summed up in 1979 by Dr. Price, a psychiatrist from Northwick Park Hospital, United Kingdom, who decried "bedside evidence" and bemoaned 


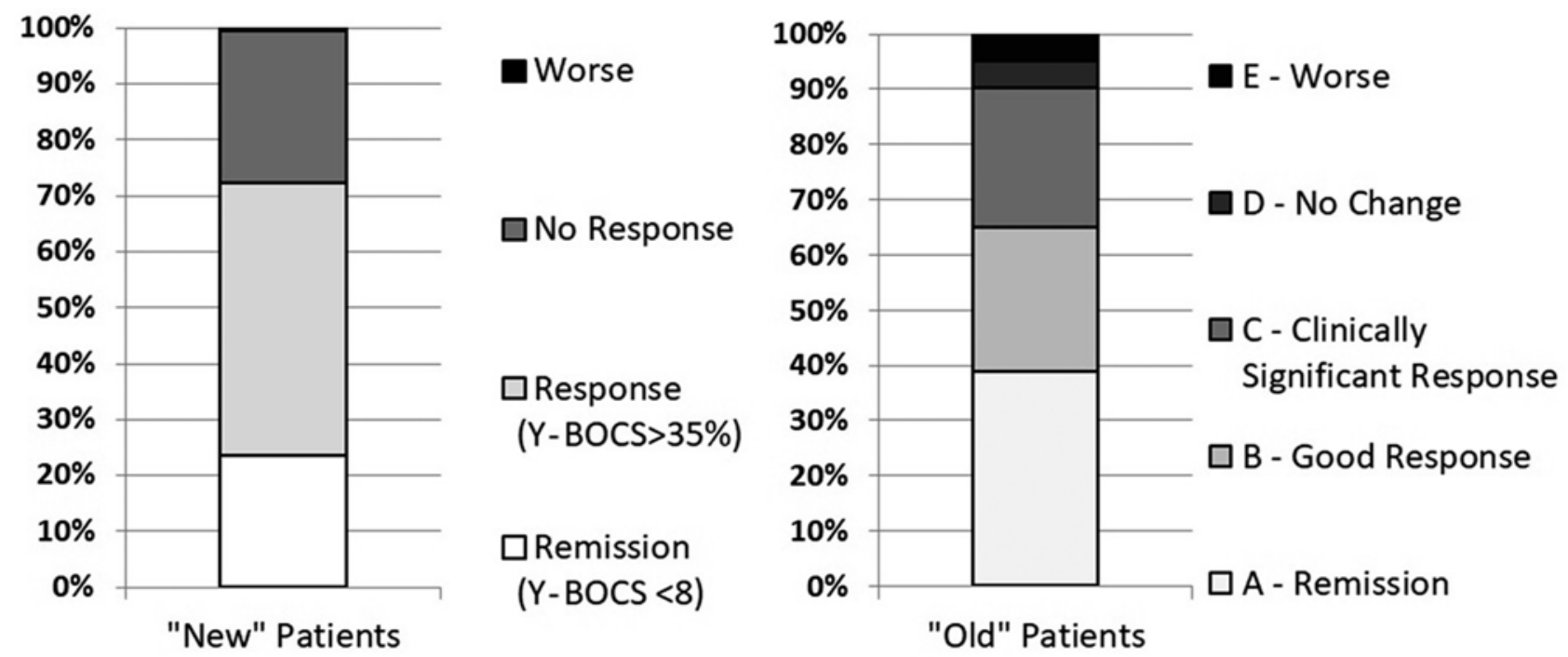

FIG. 2. Outcome by patient group. "New" and "old" refer to studies in which the Y-BOCS was used and studies in which it was not used, respectively.

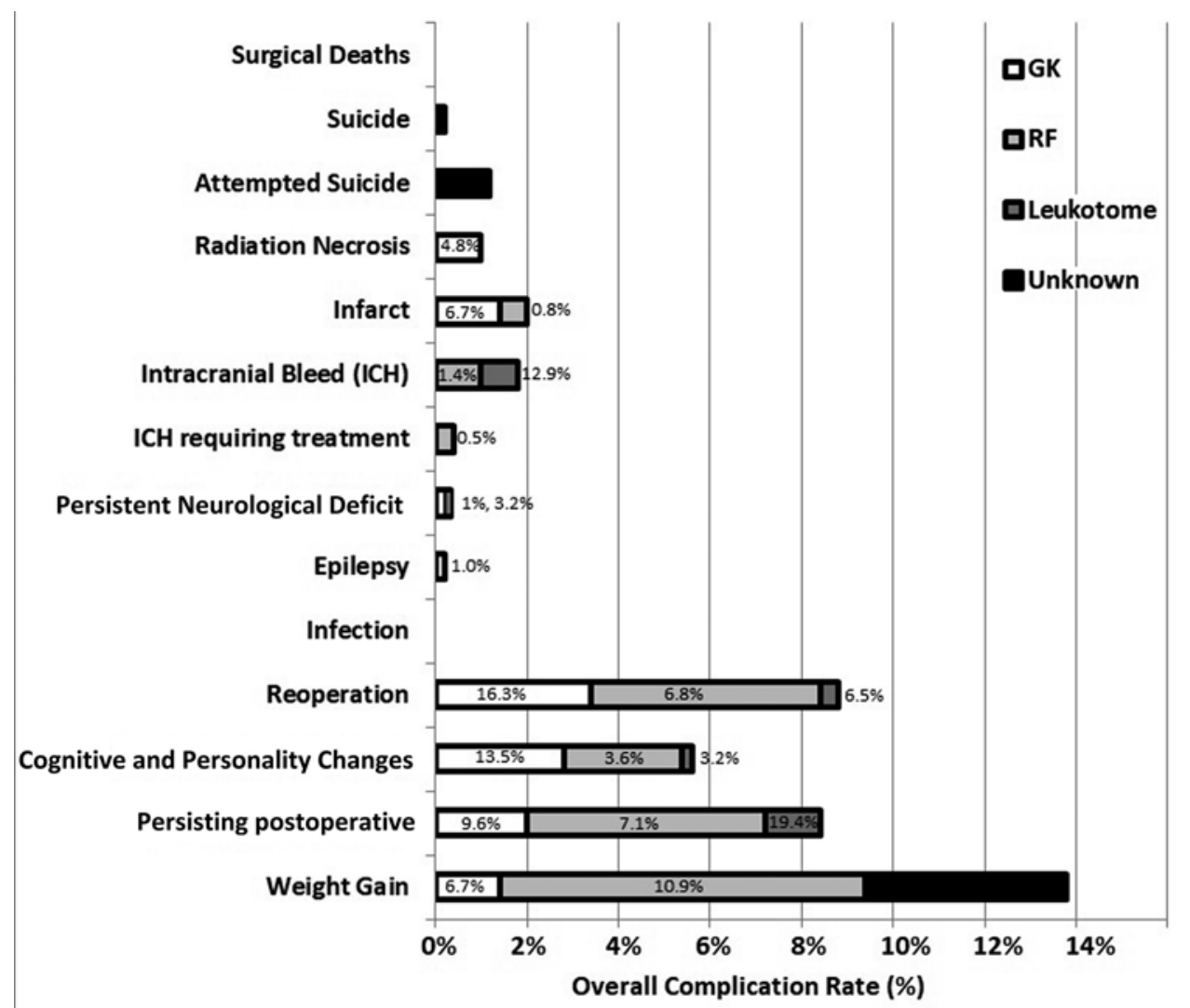

FIG. 3. Adverse events. "Persisting postoperative" refers to new-onset, often mild or nonspecific, symptoms that persisted for more than 8 weeks after surgery. These could include headache, dizziness, nausea, sleep disturbance, apathy, subtle personality changes, and other symptoms that do not fit into the other categories. The unknown group refers to patients in studies in which a mixture of surgical procedures took place and the study is not specific to which surgical group this complication occurred with. 
the lack of randomization or control groups in psychosurgery. ${ }^{33}$ This is a problem that still plagues psychosurgery in the modern era.

In "old" publications, whether by psychiatrists"1,15,36 or by neurosurgeons, ${ }^{2,25}$ patient outcome is measured by seemingly "bedside" evidence. Burzaco ${ }^{2}$ wrote an excellent paper that included robust selection criteria, meticulous recording of side effects, and prognosis. In evaluation of outcome, the psychiatrists', patients', and relatives' opinions were analyzed together with the degree of activity and freedom, type of medical assistance required, and use of psychometric tests by the same clinical team. While this process of evaluation was ahead of its time, it is open to significant bias.

However, in many of the older publications, follow-up processes were robust with regular meetings by the neurosurgical team and the patient/relatives. ${ }^{2}$ Often, outcome measures appear more pertinent than those used in the current era; indeed, many such publications provide useful clinical vignettes about patients ${ }^{10}$ and note whether patients are achieving useful social milestones such as return to work. ${ }^{1,15,18}$ In addition, many of the older publications use recognized outcome measures of the time such as the Pippard rating scale $\mathrm{e}^{10,27}$ and CPRS-OC scale (OC subscale of the Comprehensive Psychiatric Rating Scale). ${ }^{28}$ This subjective information, although presented in older publications as a mere number in a group and again biased as a "bedside" evaluation, gives a far greater wealth of general information than a number in a scoring system, often the only available data published in "new" publications.

\section{"New" Literature}

The "new" literature, classified as those papers where a Y-BOCS score is available, showed highly successful results when $\mathrm{AC}$ was performed on the most severely affected OCD patients. Three-quarters of patients had a clinical response and 1 in 4 were considered to be in remission (Y-BOCS score < 8).

The baseline characteristic data, while not allowing for statistical comparison, appears reasonably similar to the older literature in terms of age at surgery, duration of OCD, and length of follow-up. The rate of success may appear lower in the "new" literature since more "objective" evaluations take place, in the form of Y-BOCS, global assessment of function, and other standardized tests. In many of these studies, follow-up was conducted by a member of the team not involved in the initial patient selection or surgery ${ }^{37}$ or by individuals entirely independent of the team, ${ }^{21}$ reducing the chances of bias. However, in some modern publications this was not the case, ${ }^{17,23}$ although standardized comparisons pre- and postsurgery were still used.

Selective serotonin reuptake inhibitors (SSRIs) are now considered "first-line" agents in the management of OCD. However, evidence of their efficacy only began to appear in the late 1980s; SSRIs may not have been available at the time of the publications in the "old" group, and even if one or more of these medications were available, the patients in these studies may not have received an appropriate trial of SSRI therapy prior to surgery. ${ }^{11}$ Therefore, an additional possibility for the observed outcome discrepancy between "old" and "new" literature is that patients described in the "new" publications represent a more refractory subpopulation.

The Y-BOCS rating scale is designed to be administered as a semi-structured interview to assess the severity and type of symptoms in OCD. Ten of the components of the Y-BOCS are scored from 0 (no symptoms) to 4 (incapacitating symptoms), giving a maximum score of 40 . Each of the components is not necessarily equivalent, with a different impact on quality of life. An improvement in one component may be sufficient to improve quality of life to a significant degree. Therefore, the arbitrary cutoff of $35 \%$ symptom improvement for clinical response in some respects may under-represent those who do note improvement and may explain some of the discrepancy in response rates between "new" and "old" publications.

Indeed, newer publications often suffer from over-reliance on scoring systems without evaluation of patients in their social context. Reduction of compulsions or obsessions should indeed be one aim of psychosurgery, but the chief aim should be improvement of quality of life as measured by reintegration into society, completing schooling, forming lasting relationships, etc. These more nuanced points are often lacking in newer publications..$^{21,37}$ Clinical studies reporting on fewer patients often provide detailed clinical vignettes ${ }^{3,17,38}$ that are highly useful in assessing outcome by the clinician and patient. Even the meticulously detailed 2009 Sao Paulo/Brown University publication by Lopes et al. ${ }^{23}$ flirts with this boundary, paying homage to the importance of recognizing educational attainment and work and relationship status, although it does not meaningfully elaborate on these issues with respect to patients' postoperative condition, focusing instead on a multitude of scoring systems.

\section{Adverse Effects}

There were no recorded deaths in direct relation to the surgical procedure in any publication. Based on this fact and the side effects reported in the literature spanning half a century, AC can be considered safe.

\section{Suicide and Attempted Suicide}

One suicide was noted postoperatively in the study by Rück et al. from the Swedish Karolinska Institute. ${ }^{37}$ This patient had extreme OCD and did not have any meaningful improvement despite multiple reoperations. It is unclear whether this suicide was related to the operation or underlying disease. Most authors other than the Karolinska group do not make note of postoperative suicide attempts. Rück et al. noted that many of their patients had attempted suicide preoperatively. It is probable that this pattern of behavior was not related to neurosurgery per se, although 4 of 7 patients who attempted suicide did so for the first time after surgery. Attempted suicide and suicidal ideation may occur in as many as $20 \%$ of patients with $\mathrm{OCD}^{7}$ during the illness, and importantly, a number of authors specifically note that suicidal ideation was improved postoperatively. ${ }^{10,17}$ Surgery may be viewed as a "last chance" by patients, leading them to contemplate or even attempt suicide if symptoms do not improve after AC. The importance of preoperative counseling and postoperative continuous psychiatric care (cognitive behavior therapy or other), em- 
phasizing that symptoms may take many months to improve and may continue to improve over many months, cannot be overstated. Preoperative discussion should also include the possibility of repeat surgery in order to reduce the perception that AC is a "last-ditch" therapy.

\section{Radiation Necrosis}

Rasmussen et al. ${ }^{34}$ delivered a maximum dose of 180 Gy and reported radiation necrosis in 1 patient who ultimately ended up in a minimally conscious state. Rück et al. ${ }^{37}$ reported persistent symptomatic brain edema consistent with radiation necrosis in 2 patients after a dose of 200 Gy each, well above what is now considered safe.

A dose of 140-180 Gy (maximum dose) to the ventral aspect of the anterior limb of the internal capsule is normally used to perform a GK capsulotomy. However, modern GK units deliver oblate spheroidal isocenters associated with a higher rate of late radionecrosis than older machines that delivered prolate spheroidal isocenters. Recently, efforts to recreate a prolate shape with modern machines have been suggested. ${ }^{26}$

\section{Reoperation}

One of the most significant adverse effects in this review was the reoperation rate, with reoperation being required in roughly 1 of 12 patients. Reoperations were primarily done for failure of clinical improvement or relapse of symptoms, for the most part due to small lesion size or lesion absence. ${ }^{2,6,18,27,37}$ Interestingly, lesions could not be found on postmortem examination or MRI in a set of GK capsulotomy patients from the old publication group who did not experience symptom improvement; one of these patients was exposed to only $80 \mathrm{~Gy}$ of radiation. ${ }^{27,36} \mathrm{Mini}-$ mizing the risk of reoperation by creating appropriatesized lesions is important to reduce the risk of morbidity associated with multiple capsulotomies. ${ }^{37}$

\section{Cognitive and Personality Changes}

The historical fear of frontal lobe syndrome or aberrant cognitive and personality changes following stereotactic capsulotomy does not appear to be well founded on review of the literature. While many of these studies do not publish the results of psychometric or personality tests, $, 2,18,36$ most make note of personality and cognitive traits and generally report that these traits improve. If the traits worsen, the worsening either is temporary or does not have a meaningful effect on quality of life. Some report a more mixed picture, with some patients reporting marked fatigability years after surgery while others completed doctoral dissertations or staged public art exhibitions. ${ }^{1}$

In newer studies, where multiple psychometric, personality, and cognitive tests are performed, and adverse effects are thoroughly documented, the phenomenon of reduced initiative, apathy, and fatigability tends to be temporary. ${ }^{3,5,23}$ However, Rück et al. ${ }^{37}$ noted significant frontal lobe dysfunction in 10 (43\%) of 23 patients using their own Execution, Apathy and Disinhibition Scale (EAD Scale) and compromised executive function in 6 of 7 patients tested using the Wisconsin Card Sorting Test at long-term follow-up. It must be noted that there was no presurgical evaluation of these patients and that 5 of 14 patients who suffered cognitive/personality side effects had undergone GK radiosurgery with doses ranging from 180 to $200 \mathrm{~Gy}$. It is therefore difficult to ascertain whether cognitive findings were present prior to surgery or only subsequent to excessive radiation doses. Gouvea et al. ${ }^{13}$ also reported on a patient who performed worse on tests of frontal lobe function after AC, although this did not affect the patient's everyday life. In a study of 35 patients, Liu et al. reported that 9 patients suffered temporary cognitive defects and organic brain syndrome, noting permanent and marked personality changes in $2(5.7 \%)$ of 35 patients. $^{21}$

\section{Weight Gain}

Weight gain is a well-documented side effect of AC for OCD in both older ${ }^{1,2,15}$ and newer publications..$^{5,37}$ It is extremely difficult to know whether or not weight gain and increased appetite is a specific by-product of capsulotomy. Perhaps patients who have been socially isolated with many of the comorbid diagnoses that often accompany OCD regain their appetite after relief of the vast symptom burden that previously dictated their daily routine. Weight gain is also a well-documented side effect in patients receiving medical treatment for a variety of psychiatric disorders. ${ }^{32,41}$

\section{Adverse Effects by Lesion Method}

The rate of serious and persistent complications is low and similar in different lesion methods, with a few notable exceptions. The rate of $\mathrm{ICH}$ is markedly higher in capsulotomy with a mechanical leukotome compared to other methods, resulting in persistent neurological deficit in 1 patient and a myriad of ongoing symptoms in a number of other patients. The rate of cerebral infarct was higher in patients who underwent GK capsulotomy compared to other methods, although the vast majority of these infarcts were asymptomatic and only evident on routine postoperative imaging.

The rate of reoperation was higher in patients who underwent GK capsulotomy, often due to clinical nonresponse. Rasmussen and colleagues ${ }^{34}$ reported that a single GK shot located centrally in the capsule was ineffective. After a second more ventrally placed lesion a noticeable clinical improvement was observed, to produce similar response rates to patients who underwent a double shot.

In more modern studies, patients are proactively screened for all adverse effects. Indeed, this is done with varying degrees of effectiveness, vigor, and methodological quality among studies, making a direct head-to-head comparison between surgical methods challenging.

\section{The Rise, Fall, and Reemergence of AC}

As can be clearly seen from Fig. 1, there was clear interest in stereotactic AC for OCD from 1960 to 1980. Many of the studies were of high quality with rigorous patient selection criteria, given available scales at the time. Overall, the results were positive, so it may seem strange that $\mathrm{AC}$ should fall so completely and so quickly from the armamentarium for the treatment of severe, medicationrefractory, and in many cases life-threatening OCD.

By the 1960 s some 60,000 or so transorbital "ice-pick" lobotomies, popularized and aggressively promoted by 
neurologist Walter Freeman, had been performed in the United States. ${ }^{35}$ The backlash against all psychosurgery coincided with celebrities such as Rosemary Kennedy (President Kennedy's sister) and Warner Baxter (1950s' Hollywood actor) suffering complete cognitive destruction or death after lobotomy. At that time, many countries entirely banned psychosurgery. Additionally, the development and introduction of pharmacological agents, such as chlorpromazine and haloperidol in the $1950 \mathrm{~s}$, for the treatment of previously untreatable psychiatric conditions contributed to the demise of lobotomy and, with it, all forms of psychosurgery. The media also played an important role in establishing the antisurgical zeitgeist with respect to mental disorders, especially with Milos Forman's screen adaptation of Ken Kesey's book One Flew Over the Cuckoo's Nest, released in 1975.

The resurgent interest in stereotactic psychosurgery started following the popularization of DBS for movement disorders and its first applications in patients with OCD by Nuttin et al., ${ }^{29}$ who targeted with DBS the same "old" lesional target for OCD. Their publication helped to reinvigorate interest in stereotactic lesional surgery for OCD from early 2000 onward. Indeed, this same group has used $\mathrm{AC}$ as a "rescue procedure" after unsatisfactory DBS of the anterior capsule region, reporting treatment success in 2 of 3 patients. ${ }^{24}$ In another publication, they reported better Y-BOCS outcomes in a cohort of capsulotomy patients than in a cohort of DBS patients. ${ }^{39}$

\section{Deep Brain Stimulation}

When targeting the ventral capsule surgically, many groups tend to favor DBS over stereotactic ablation. Although there are no head-to-head comparisons, a recent review suggests that these techniques have similar safety profiles, but that stereotactic ablation may be associated with greater efficacy, without the high costs associated with implanted hardware and lifelong maintenance. ${ }^{31}$

\section{Limitations of This Review \\ Group Data}

Group data rather than individual data was available for analysis in almost all the "old" publications $\mathbf{s}^{1,2,18,25,28,36}$ and a smaller number of more modern publications. 5,6,20,21,30 This poses a number of problems for analysis. The first is that any deductions are subject to the ecological fallacy. This fallacy means that the outcome of individuals is presupposed by the outcome of the group. Thus, large positive outliers in a few patients can vastly skew results positively even if a treatment has failed. The opposite is also true. In the publication by Liu et al. ${ }^{21}$ the mean postoperative Y-BOCS score was 4.4 at 36 months after surgery, an overall average improvement of almost $80 \%$. Thus all patients were noted to be in remission. However, there may have been a number who did not respond or were worse off and were not counted in the analysis. Of note, the standard deviation of the 36-month postoperative Y-BOCS score was 2.3 , meaning that at least in this publication the majority of patients would have had a Y-BOCS score $<8$ at long-term follow up. However, in the publication by Oliver et al., ${ }^{30}$ no standard deviation values are available. All patients were considered to have been "responders," but large numbers of these patients may have gone into remission or have experienced worsening of symptoms.

\section{Comparison Between "Old" and "New" Data}

Direct comparison between "old" and "new" data could not be performed, due mostly to the use of different outcome and diagnostic criteria and the availability of key data for analysis.

\section{Reoperation}

Although every effort was made to remove duplicate patients, it is possible that some patients were reported twice (after the first and second operation).

\section{Meta-Analysis}

Equally, it was not possible to perform a formal metaanalysis, as the publications available were mostly small case reports or series without control groups.

\section{Conclusions}

Anterior capsulotomy is a highly effective treatment for OCD with a favorable side-effect profile. Detailed clinical vignettes should be encouraged for each reported case. This could be included in publications as supplementary material. Tabulated information to include categories of education, sexual relationships, platonic relationships, and employment would also be useful. GK doses of more than 180 Gy and the use of a leukotome are both associated with more adverse effects and should be avoided. AC has been an underused treatment, which has contributed to a paucity of high-level evidence for its use. Psychiatrists should consider neurosurgery, including AC, when confronted with patients with severe refractory OCD. An increase in referrals to specialist neurosurgical centers will allow further good-quality research to improve understanding of the future role of stereotactic $\mathrm{AC}$ in managing severe refractory OCD.

\section{References}

1. Bingley T, Leksell L, Meyerson B, Rylander G: Stereotactic anterior capsulotomy in anxiety and obsessive-compulsive states, in Sweet WH, Obrador S, Martin Rodriguez JG (eds): Neurosurgical Treatment in Psychiatry, Pain and Epilepsy. Baltimore: University Park Press, 1977

2. Burzaco J: Stereotactic surgery in the treatment of obsessivecompulsive neurosis, in Perris C, Struwe G, Janssen B (eds): Biological Psychiatry. Proceedings of the Third World Congress on Biological Psychiatry. Amsterdam: Elsevier, 1981

3. Christensen DD, Laitinen LV, Schmidt LJ, Hariz MI: Anterior capsulotomy for treatment of refractory obsessivecompulsive disorder: results in a young and an old patient. Stereotact Funct Neurosurg 79:234-244, 2002

4. Cosgrove GR: Surgery for psychiatric disorders. CNS Spectr 5:43-52, 2000

5. Csigó K, Harsányi A, Demeter G, Rajkai C, Németh A, Racsmány M: Long-term follow-up of patients with obsessivecompulsive disorder treated by anterior capsulotomy: a neuropsychological study. J Affect Disord 126:198-205, 2010

6. D'Astous M, Cottin S, Roy M, Picard C, Cantin L: Bilateral stereotactic anterior capsulotomy for obsessive-compulsive 
disorder: long-term follow-up. J Neurol Neurosurg Psychiatry 84:1208-1213, 2013

7. Dhyani M, Trivedi JK, Nischal A, Sinha PK, Verma S, et al: Suicidal behaviour of Indian patients with obsessive compulsive disorder. Indian J Psychiatry 55:161-166, 2013

8. Doshi PK: Anterior capsulotomy for refractory OCD: First case as per the core group guidelines. Indian J Psychiatry 53:270-273, 2011

9. Fineberg NA, Gale TM: Evidence-based pharmacotherapy of obsessive-compulsive disorder. Int J Neuropsychopharmacol 8:107-129, 2005

10. Fodstad H, Strandman E, Karlsson B, West KA: Treatment of chronic obsessive compulsive states with stereotactic anterior capsulotomy or cingulotomy. Acta Neurochir (Wien) 62:1-23, 1982

11. Fontenelle LF, Nascimento AL, Mendlowicz MV, Shavitt RG, Versiani M: An update on the pharmacological treatment of obsessive-compulsive disorder. Expert Opin Pharmacother 8:563-583, 2007

12. Goodman WK, Price LH, Rasmussen SA, Mazure C, Fleischmann RL, Hill CL, et al: The Yale-Brown Obsessive Compulsive Scale. I. Development, use, and reliability. Arch Gen Psychiatry 46:1006-1011, 1989

13. Gouvea F, Lopes A, Greenberg B, Canteras M, Taub A, Mathis M, et al: Response to sham and active gamma ventral capsulotomy in otherwise intractable obsessive-compulsive disorder. Stereotact Funct Neurosurg 88:177-182, 2010

14. Hariz MI, Blomstedt P, Zrinzo L: Deep brain stimulation between 1947 and 1987: the untold story. Neurosurg Focus 29(2):E1, 2010

15. Herner T: Treatment of mental disorders with frontal stereotactic thermal lesions. A follow up of 116 cases. Acta Psychiatr Scand Suppl 36:941, 1961 (Abstract)

16. Kim SJ, Roh D, Jung HH, Chang WS, Kim CH, Chang JW: A study of novel bilateral thermal capsulotomy with focused ultrasound for treatment-refractory obsessive-compulsive disorder: 2-year follow-up. J Psychiatry Neurosci 43:327-337, 2018

17. Kondziolka D, Flickinger JC, Hudak R: Results following gamma knife radiosurgical anterior capsulotomies for obsessive compulsive disorder. Neurosurgery 68:28-33, 2011

18. Kullberg G: Differences in effect of capsulotomy and cingulotomy, in Sweet WH, Obrador S, Martin-Rodriguez JG (eds): Neurosurgical Treatment in Psychiatry, Pain and Epilepsy. Baltimore: University Park Press, 1977, pp 301-308

19. Lévêque M: A controversial past, in Psychosurgery. New Techniques for Brain Disorders. Cham, Switzerland: Springer International Publishing, 2014, pp 28-30

20. Liu HB, Zhong Q, Wang W: Bilateral anterior capsulotomy for patients with refractory obsessive-compulsive disorder: a multicenter, long-term, follow-up study. Neurol India 65:770-776, 2017

21. Liu K, Zhang H, Liu C, Guan Y, Lang L, Cheng Y, et al: Stereotactic treatment of refractory obsessive compulsive disorder by bilateral capsulotomy with 3 years follow-up. J Clin Neurosci 15:622-629, 2008

22. Lopes AC, Greenberg BD, Canteras MM, Batistuzzo MC, Hoexter MQ, Gentil AF, et al: Gamma ventral capsulotomy for obsessive-compulsive disorder: a randomized clinical trial. JAMA Psychiatry 71:1066-1076, 2014

23. Lopes AC, Greenberg BD, Norén G, Canteras MM, Busatto GF, de Mathis ME, et al: Treatment of resistant obsessivecompulsive disorder with ventral capsular/ventral striatal gamma capsulotomy: a pilot prospective study. J Neuropsychiatry Clin Neurosci 21:381-392, 2009

24. Luyten L, Hendrickx S, Raymaekers S, Gabriëls L, Nuttin B: Electrical stimulation in the bed nucleus of the stria terminalis alleviates severe obsessive-compulsive disorder. Mol Psychiatry 21:1272-1280, 2016
25. Martinez SN, Bertrand C, Negro PMM, Perez-Calvo JM: Alteration of pain perception by stereotactic lesions of frontothalamic pathways. Confin Neurol 37:113-118, 1975

26. Miguel EC, Lopes AC, McLaughlin NCR, Norén G, Gentil $\mathrm{AF}$, Hamani C, et al: Evolution of gamma knife capsulotomy for intractable obsessive-compulsive disorder. Mol Psychiatry 24:218-240, 2019

27. Mindus P, Bergström K, Levander SE, Norén G, Hindmarsh T, Thuomas KA: Magnetic resonance images related to clinical outcome after psychosurgical intervention in severe anxiety disorder. J Neurol Neurosurg Psychiatry 50:1288-1293, 1987

28. Mindus P, Meyerson B: Anterior capsulotomy for intractable anxiety disorders, in Schmidek H, Sweet WH (eds): Operative Neurosurgical Techniques. Philadelphia: W.B. Saunders Company, 1995, pp 1443-1455

29. Nuttin B, Cosyns P, Demeulemeester H, Gybels J, Meyerson B: Electrical stimulation in anterior limbs of internal capsules in patients with obsessive-compulsive disorder. Lancet 354:1526, 1999

30. Oliver B, Gascón J, Aparicio A, Ayats E, Rodriguez R, Maestro De León JL, et al: Bilateral anterior capsulotomy for refractory obsessive-compulsive disorders. Stereotact Funct Neurosurg 81:90-95, 2003

31. Pepper J, Hariz M, Zrinzo L: Deep brain stimulation versus anterior capsulotomy for obsessive-compulsive disorder: a review of the literature. J Neurosurg 122:1028-1037, 2015

32. Petersen AB, Andersen SE, Christensen M, Larsen HL: Adverse effects associated with high-dose olanzapine therapy in patients admitted to inpatient psychiatric care. Clin Toxicol (Phila) 52:39-43, 2014

33. Price JS: A paradox of psychosurgical evaluation, in Hitchcock ER, Ballantine HT, Meyerson B (eds): Modern Concepts in Psychiatric Surgery. Amsterdam: Elsevier/NorthHolland Biomedical Press, 1979, pp 337-338

34. Rasmussen SA, Noren G, Greenberg BD, Marsland R, McLaughlin NC, Malloy PJ, et al: Gamma ventral capsulotomy in intractable obsessive-compulsive disorder. Biol Psychiatry 84:355-364, 2018

35. Robison RA, Taghva A, Liu CY, Apuzzo ML: Surgery of the mind, mood, and conscious state: an idea in evolution. World Neurosurg 80:S2-S26, 2013

36. Rylander G: Stereotactic radiosurgery in anxiety and obsessive compulsive states: psychiatric aspects, in Hitchcock ER, Ballantine HT, Meyerson B (eds): Modern Concepts in Psychiatric Surgery. Amsterdam: Elsevier/North Holland Biomedical Press, 1979, pp 235-240

37. Rück C, Karlsson A, Steele JD, Edman G, Meyerson BA, Ericson K, et al: Capsulotomy for obsessive-compulsive disorder: long-term follow-up of 25 patients. Arch Gen Psychiatry 65:914-921, 2008

38. Sheehan JP, Patterson G, Schlesinger D, Xu Z: Gamma Knife surgery anterior capsulotomy for severe and refractory obsessive-compulsive disorder. J Neurosurg 119:1112-1118, 2013

39. Suetens K, Nuttin B, Gabriëls L, Van Laere K: Differences in metabolic network modulation between capsulotomy and deep-brain stimulation for refractory obsessive-compulsive disorder. J Nucl Med 55:951-959, 2014

40. Vos T, Mathers CD: The burden of mental disorders: a comparison of methods between the Australian burden of disease studies and the Global Burden of Disease study. Bull World Health Organ 78:427-438, 2000

41. Walsh KH, McDougle CJ: Pharmacological augmentation strategies for treatment-resistant obsessive-compulsive disorder. Expert Opin Pharmacother 5:2059-2067, 2004

42. Woerdeman PA, Willems PWA, Noordmans HJ, Berkelbach van der Sprenkel JW, van Rijen PC: Frameless stereotactic subcaudate tractotomy for intractable obsessive-compulsive disorder. Acta Neurochir (Wien) 148:633-637, 2006 
43. Zhan S, Liu W, Li D, Pan S, Pan Y, Li Y, et al: Long-term follow-up of bilateral anterior capsulotomy in patients with refractory obsessive-compulsive disorder. Clin Neurol Neurosurg 119:91-95, 2014

\section{Disclosures}

L.Z. and M.H. both report receipt of honoraria and/or travel expenses from Medtronic and Boston Scientific for speaking at meetings.

\section{Author Contributions}

Conception and design: all authors. Acquisition of data: Pepper, Zrinzo. Analysis and interpretation of data: all authors. Drafting the article: all authors. Critically revising the article: all authors. Reviewed submitted version of manuscript: all authors. Approved the final version of the manuscript on behalf of all authors:

Pepper.

\section{Supplemental Information}

Online-Only Content

Supplemental material is available with the online version of the article.

Supplemental Tables 1-7. https://thejns.org/doi/suppl/10.3171/ 2019.4.JNS19275.

\section{Previous Presentations}

Portions of this work were presented in abstract form at the European Society for Stereotactic and Functional Neurosurgery Congress, September 2018, Edinburgh, Scotland.

\section{Correspondence}

Joshua Pepper: Queen Elizabeth Hospital, Birmingham, United Kingdom. joshua.pepper1@nhs.net. 